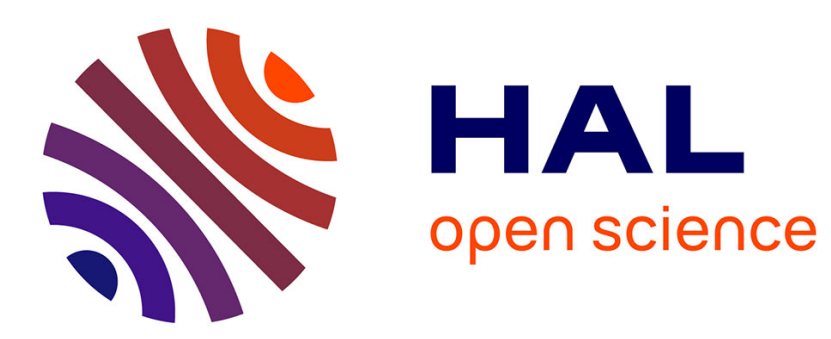

\title{
Towards Industry 4.0: Increased Need for Situational Awareness on the Shop Floor
}

\author{
Marta Lall, Hans Torvatn, Eva Amdahl Seim
}

\section{To cite this version:}

Marta Lall, Hans Torvatn, Eva Amdahl Seim. Towards Industry 4.0: Increased Need for Situational Awareness on the Shop Floor. IFIP International Conference on Advances in Production Management Systems (APMS), Sep 2017, Hamburg, Germany. pp.322-329, 10.1007/978-3-319-66923-6_38 . hal01666208

\section{HAL Id: hal-01666208 \\ https://hal.inria.fr/hal-01666208}

Submitted on 18 Dec 2017

HAL is a multi-disciplinary open access archive for the deposit and dissemination of scientific research documents, whether they are published or not. The documents may come from teaching and research institutions in France or abroad, or from public or private research centers.
L'archive ouverte pluridisciplinaire HAL, est destinée au dépôt et à la diffusion de documents scientifiques de niveau recherche, publiés ou non, émanant des établissements d'enseignement et de recherche français ou étrangers, des laboratoires publics ou privés. 


\title{
Towards Industry 4.0: Increased need for situational awareness on the shop floor
}

\author{
Marta Lall, Hans Torvatn and Eva Amdahl Seim \\ SINTEF Technology and Society, Industrial Management P.O. Box 4760 Sluppen, N-7465 \\ Trondheim, Norway \\ marta.lall@sintef.no
}

\begin{abstract}
Currently, much attention is given to the technological opportunities and challenges that "Industry 4.0" entails. However, though the change towards Industry 4.0 is driven by technology, this industrial revolution is not strictly technological. The human aspect of Industry 4.0 is still an emerging field, and must be further researched if modern manufacturers are to reach their full potential. While manufacturers have a high focus on modernizing production processes, the accelerating automation and consequent increasing complexity of tasks is not accompanied by the necessary support for the operator. This results in inefficiency and non-optimal use of workers' capabilities and potential. We argue that operators need technical support systems for increased situation awareness, to be able to efficiently handle an increased pace and complexity of tasks. Our empirical evidence shows that this is not only valid for high-tech manufacturing, but can also be seen in "traditional" manufacturing. We use case studies from three Norwegian manufacturers to illustrate how digitization is yet to reach the operator.
\end{abstract}

Keywords: Industry 4.0, situation awareness, human-centred manufacturing

\section{Introduction}

"In its scale, scope and complexity, what I consider to be the fourth industrial revolution is unlike anything humankind has experienced before" [2].

Although the change towards Industry 4.0 is driven by technology, this industrial revolution is not strictly a technological one. Whenever the technical system changes in the workplace, it has an effect in the social (or human) system, and vice versa [3]. In fact, work organisation is said to be one of the largest challenges with implementing industry 4.0 [4]. Despite this, the human aspects of Industry 4.0 are largely under-researched. The change towards industry 4.0 will likely result in an increase in responsibility and authority of production for the operator, with a high degree of autonomy [4]. As machines become smarter, the operators will also become responsible for the production as a whole, and not just a single machine [5]. Operators are

adfa, p. 1, 2011.

(C) Springer-Verlag Berlin Heidelberg 2011 
the manufacturing managers of the future, and will only delegate tasks to a higher level in case of exceptions [5]. This increased autonomy emphasizes the importance of operators ability to act on own initiative and organize own work [4]. Thus, we argue that operators need comprehensive knowledge about their production processes, knowledge that is typically found at a managerial level and not shop floor level today. In the area of maintenance there are some examples of systems providing information to shop-floor personnel $[6,7]$, but for support in daily operations little has been done. Regardless of the work task being maintenance, production or otherwise the overall challenge remains the same: The autonomous operator needs assistance systems that aggregate and visualize information comprehensibly, to make informed decisions and solve urgent problems effectively [5]. Operators should be provided with decision support to match their new decision authority.

As manufacturing becomes ever more high-tech, the work content and required skills for operators will change dramatically [8]. Industry 4.0 literature outlines how the new work of the operator in manufacturing is expected to change towards having more responsibility for production and complex decision-making. As automation eliminates repetitive, low skill work, the human role is changing from simpler manual tasks to more complex decision-making [9]. The operator will reorganize, reconfigure, and maintain the system, and will have a key role in quality assurance $[4,9]$.

With the increasing complexity and pace of production in the new manufacturing reality, increased situational awareness (SA) for the operator is essential. SA is "the perception of the elements in the environment within a volume of time and space, the comprehen-

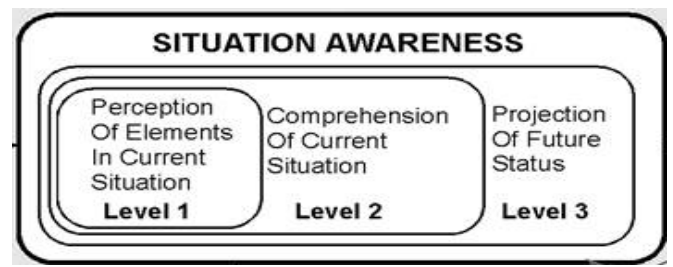

Fig. 1. - The three levels of SA [1] sion of their meaning and the projection of their status in the near future" [10]. SA is commonly divided into three levels of perception (see figure 1). In manufacturing, SA is necessary for the operators to deal with a complex and unexpected situation in an effective manner, namely to decide and act timely and appropriately [11].

\section{$2 \quad$ Method}

As part of an on-going research project about highly automated and flexible manufacturing, the researchers have observed and participated in operators work in three case companies. The research has been conducted following the participative tradition of action research. In action research, the professional researcher and the stakeholders together define the problems to be examined, co-generate relevant knowledge about them, learn and execute social research techniques, take actions, and interpret the results [12].

To structure the case studies a topical framework for mapping was made, containing both methodological descriptions of how the researcher were to conduct the stud- 
ies, and which topics to investigate. The topics covered a broad spectrum of issues, with the following headings: Production system, the team, quality, information and communication, management. Data collection methods have been qualitative, with a mix of observation, participation, unstructured and semi-structured interviews [13]. Results of the initial mappings were gathered in a report and sent back to the case companies for validation. When a set of problems were mapped and validated, further workshops were held with operators and production management to discuss the development and implementation of test cases of technical support systems for operators to solve some of the identified issues. The development of such test cases is still on going at the time of this paper.

\section{Case descriptions}

All three case companies are Norwegian manufacturers, with several hundred employees and international markets. They have different levels of automation, from high to low, and so we have named them accordingly: Robots In Line (RIL), Automated Machine Cells (AMC) and Pretty Manual Line (PML).

Robots in Line (RIL)

RIL has a highly automated production line, with robots doing most of the work. In the department investigated, there are only two operators at the shop floor. Operators load/unload parts to the line, do quality measurement, maintenance, reconfiguration of the line, and solve errors. Even with advanced technology in production, the information flow to operators is still based on conversation, or manually written media such as paper, e-mail or whiteboards. Operators receive most information by conversations with factory managers. Whiteboards are used extensively in the factory, depicting a multitude of information including production and quality performance. However, operators claim that the only information they actually use from the whiteboards are production plans. Issues incurred during the shift is written by hand in a book, for the next shift leader to see, and for improvement work.

The case study revealed a multitude of issues relating to information flow at the shop floor. However, in this large line with few operators, what the operators wanted most was a tool to provide an overview in production. Signal lamps dispatched across the line are not visible from other parts of the line, and operators have to constantly move along the line or rely on their hearing to know if there is a problem - if it is too quiet, something is wrong. Operators want to be notified immediately if there is an error in a machine, regardless of where they are when the error occurs. They say this would reduce stress and unnecessary walking from having to "go and check", and contribute to reduced downtime because of faster response to errors. To be better able to plan their work short term operators would also like to know if there is a low level in any of the feeders for input materials. This will eliminate downtime resulting from the operator not seeing that feeders need to be restocked. For simplicity with programming and installation, the company has chosen to display 
the information on screens first. This is a cheap and quick solution, which allows the company to test the usability of the information solution and re-design it to fit the operators' needs.

\section{Automated Machine Cells (AMC)}

AMC's production is organized as functional cells, with a complex production flow. Each machine is highly automated; once the program is started, machines perform operations without interference from the operator. The operators' main tasks are to load/unload items to the machine, start machines, change tools as needed, and monitor machines in case of malfunctions. Operators receive information mainly from other people in the factory, and from whiteboards and production notes.

Machine errors are an everyday issue at AMC. Signal lamps on the machines indicate errors, but these lamps can only be seen if you are nearby. With daily machine errors, the response time to errors significantly affect machine downtime. Thus, the operator needs to be nearby the machine in order to quickly detect and solve errors. With long processing times in most of the machines, monitoring accounts for a large part of operators' time, time that could be utilized better if the operator did not have to remain nearby the machine. In addition to the lamps, operators also depend on hearing to monitor machines. To increase operator mobility, operators need a mobile solution providing the same situational awareness as sitting by the machine. Such a mobile solution would allow the operator to move freely in the production facility, enabling the operators to handle several machines at once, or to work in teams. To achieve this, AMC has begun testing the use of smart watches for operators.

Due to numerous sources of variance, such as machine errors, each cell at AMC experiences large variations in production flow. Even the bottlenecks occasionally experience lack of work. To handle this, AMC has dedicated production coordinators working in the factory. These coordinators keep track of in-house inventory and progress in production. Although the coordinators do not have formal responsibility for production, they are key decision-makers - making decisions about what to produce and when. Operators receive the information they need about production flow from these coordinators, in addition to managers, and find the information from the coordinator useful and important. Without the coordinators chaos would rise. Although coordinators make decisions in production, their main function is to collect and analyse information. If operators were given appropriate information and decision support, coordinators would not be needed to organize flow. At a later stage, AMC might try to dispatch such information to the operators' smart watches. However, the issue with the machine alarms currently holds higher priority and AMC is experimenting with these now. 
Pretty Manual Line (PML)

PML has a traditional production line. There is a low level of automation, with the machines performing simple, single tasks. The operators main work is to perform several manual tasks, such as to load products into the machines, run the machines, manually add materials/parts to the main products, and move products between different machines. The operators' main source of information is conversations with the manager and process engineer. Each operator team also has a whiteboard, to keep track of key information for their part of the production. Just as in the two cases above with more automated production, the flow of information at PML's shop floor is not automated or digital.

Operators at PML relate to the daily production target for their part of the line, and seemingly lack any information about the rest of production. PML's production area is divided into several buildings, and it is difficult to have a complete overview of production progress. It was only by chance we observed a key information channel for value chain information to the operator; namely the forklift driver. Because the forklift driver moves the products along the production line between buildings and storages, the forklift-driver attains an overview of production and inventory status across the whole production line. Thus, one can ask the forklift-driver about the status in other parts of production. Operators at PML have done so to the extent that it has become part of the driver's job to convey information between buildings. This was discovered during our observation of production, as the forklift-driver called out "8000" when entering the building - which turned out to be the number of items in an intermediate storage. The information conveyed by the forklift-driver helps operators to make decisions about when and where to dispatch batches.

Although the needed information might be available in the computer system, the operators prefer to ask the forklift driver. This is partly due to a cumbersome computer system and partly due to lack of knowledge about what information exists in the computer system. Asking the forklift-driver is the fastest option. Similar to RIL, PML will run tests with displaying information on screens for the operators. The operators are heavily involved in the design process. In addition to machine alarms, the screens will likely contain information that currently is written on whiteboards, and information about production in other buildings.

\section{$4 \quad$ Analysis}

Some common themes can be seen in the cases:

1. The operators need for information about the production

2. The inability of current computer systems to deliver information to the operators

3. The emergence of local solutions to get the needed information

First, in all three cases we can see clear evidence that operators in fact need more information than what is provided. Operators lack relevant, valid and updated in- 
formation about the production system, and are completely dependent upon their managers and others who decide which information is relevant to convey. After a process of mapping what information the operators want most, the operators request support to increase their situational awareness (SA), a need that results from the increase in automation and reduction of the number of operators in the factory. To reduce downtime of machines, operators want to be notified immediately if there is an error in a machine, regardless of where they are when the error occurs. At AMC, a mobile SA support system can also facilitate the formation of operator teams because it will allow the operators to move away from their designated machine cells. It is likely that future operators will have to work in teams to solve complex problems.

Although the three cases are at different levels when it comes to production technology, they are similar when it comes to how the operator receives information. Even in the case of RIL with almost full automation, the information flow to operators is still based on conversation, or manually written media such as paper, e-mail or whiteboards. Although information is largely digitalized and somewhat automated at the managerial level, at operator level all three cases are in the "paper age". This is not unique; a large survey done in 2016 in the Norwegian industrial sector shows that in general digitalization is yet to reach the operator [14].

The second point is that although information systems exist with relevant information, operators do not use such systems to get information. In all three cases, the operators have some access to IT-systems. The operator's relation to these IT systems is to feed information into the system, so others can get information. All the case companies have various IT systems keeping track of production, with sensors measuring status in real time. However, this information is used by managers and process engineers, not operators. Most of the information that operators request, such as notifications about stops, errors, and low levels in feeders, already exists on some PLC system or a server, but is not available in real time to the operator. The lack of information systems for operators is contradictory to requirements described in Industry 4.0 literature. For instance, Herman et al. [5] argue that the autonomous operator will require assistance systems to aggregate and visualize information comprehensibly, in order to make informed decisions and solve urgent problems effectively.

The main reason that operators do not use IT systems is because the systems are made for managers. In addition, there are many different, disintegrated computer programs in each company, and managers spend a lot of their time wrestling with cumbersome user interfaces. To be useful, IT systems must be tailored to be people that are to use it. As operators are key decision makers in production, operators should be considered as the primary user of information systems in production [15]. In the case companies, the effect of involvement in information systems can be seen from how operators use the whiteboards. At RIL operators say that the only information they actually use from the numerous whiteboards are production plans. At $\mathrm{PML}$ the case is different - here the operators find the whiteboards very useful. They 
have designed their own whiteboards, and are free to change them as they want to, while at RIL the boards are company standard. In the same way that operators should be able to create their own whiteboards, they should get to configure visualisation of their own digital information systems.

Third, in all cases we observe that some workaround has emerged to deal with the lack of information. To convey information about production is not part of the forklift driver's job description, but a task that has emerged from an unsolicited need for information. At AMC, they have operators "baby sit" machines in case of errors, and the coordinator is manually collecting and analysing information to maintain production flow. At RIL, the operators solve their need for information simply by constantly moving around in the production facility to check that everything is running smoothly. In all cases humans have stepped up to keep the crucial information flow going in production. However, these solutions have obvious weaknesses. If the coordinator at AMC or forklift driver at PML are absent, the operators are left "blind", or have to spend time gathering information instead of maintaining productivity.

\section{Conclusion}

We see technical support systems that increase the situational awareness for operators as a first, important step towards optimized Industry 4.0 manufacturing, and a key to sustained competitive advantage in modern manufacturing. There is no doubt that operators in the case companies have an unsolicited need for information, and that the lack of such information is negatively affecting either productivity, or profits, or both. Existing IT-systems are not made for operators, and alternative information channels have emerged in production. There is a need for efficient managing of information, where information is displayed to the user according to the user's current needs $[15,16]$, to help operators deal with the increased amount and richness of communication. The highly motivated operators currently lack the information they need to be able to maximize their own productivity.

\begin{tabular}{|l|l|l|}
\hline Element & Current & Future (Industry 4.0) \\
\hline Operator role & Operator of machines & Manager of machines \\
\hline Task complexity & Medium & High \\
\hline Required level of SA & Level 1 & Level 2 \\
\hline Pace & High & Higher \\
\hline $\begin{array}{l}\text { Autonomy/ decision } \\
\text { authority }\end{array}$ & Managed operators & Autonomous operators and teams. \\
\hline Responsibility & Single machine & Whole production \\
\hline Information support & Made for managers & $\begin{array}{l}\text { Real-time decision-support for } \\
\text { operators }\end{array}$ \\
\hline
\end{tabular}

Table 1. Summary of elements that change with Industry 4.0

We have no indication that the three case companies are lagging behind the rest of the Norwegian (or to the degree we know it, European) industry. Rather, we believe this situation to be typical for all industry: Information systems are tailored to the 
needs of management, and ignores the need for situational awareness for the operators.

The information solutions we have designed together with the operators are merely at the first level of SA - the perception of element in current situation (see figure 1). Our experience is that it is difficult to envision a future state of your own work, and that is the reason for the low level of ambition in designing information systems. We find that in most people's vision about the future factory, operators are mainly doing the same task, but then on more than one machine at the time. In Industry 4.0 operators will take on tasks that are currently performed by managers. This means operators will need the information managers currently have exclusive access to, but they will not have the same amount of time to find and analyse this information. The operator is the future manager in manufacturing.

1. Endsley, M.R. and D.J. Garland, Situation awareness analysis and measurement. 2000: CRC Press.

2. Schwab, K., The fourth industrial revolution. 2017: Penguin UK.

3. Knutstad, G. and J.E. Ravn. Technology utilization as competitive advantage-a sociotechnical approach to high performance work systems. in Advanced Materials Research. 2014. Trans Tech Publ.

4. Kagermann, H., et al., Recommendations for Implementing the Strategic Initiative INDUSTRIE 4.0: Securing the Future of German Manufacturing Industry; Final Report of the Industrie 4.0 Working Group. 2013, Forschungsunion.

5. Hermann, M., T. Pentek, and B. Otto. Design Principles for Industrie 4.0 Scenarios. in 2016 49th Hawaii International Conference on System Sciences (HICSS). 2016.

6. Sipsas, K., et al., Collaborative maintenance in flow-line manufacturing environments: An Industry 4.0 approach. Procedia CIRP, 2016. 55: p. 236-241.

7. Mourtzis, D., A. Vlachou, and V. Zogopoulos, Cloud-Based Augmented Reality Remote Maintenance Through Shop-Floor Monitoring: A Product-Service System Approach. Journal of Manufacturing Science and Engineering, 2017. 139(6): p. 061011.

8. EFFRA, Factories of the future - Multi-annual roadmap for the contractual PPP under Horizon 2020. 2013, Publications Office of the European Union: Luxembourg.

9. Programmabureau Smart Industry. Smart Industry - Dutch industry fit for the future. 2014; Available from: http://www.smartindustry.nl/wpcontent/uploads/2014/07/Opmaak-Smart-Industry.pdf.

10. Endsley, M.R., Design and Evaluation for Situation Awareness Enhancement. Proceedings of the Human Factors Society Annual Meeting, 1988. 32(2): p. 97-101.

11. Meyer, G.G., J.C. Wortmann, and N.B. Szirbik, Production monitoring and control with intelligent products. International Journal of Production Research, 2011. 49(5): p. 1303-1317.

12. Greenwood, D.J. and M. Levin, Introduction to action research: Social research for social change. 2006: SAGE publications.

13. Yin, R.K., Case study research: Design and methods. 2013: Sage publications.

14. Norsk Industri, Konjunkturrapport 2016. 2016.

15. International Society of Automation, ISA 101, Human-Machine Interfaces. 2015.

16. Lee, A.N.N., et al. Pro-active content managing system for efficient human machine interaction in data intensive environments. in Industrial Informatics (INDIN), 2013 11th IEEE International Conference on. 2013. 